\title{
Large larvae of a flush-feeding moth (Epirrita autumnata, Lepidoptera: Geometridae) are not at a higher risk of parasitism: implications for the moth's life-history
}

\author{
TiIT TEDER ${ }^{1,2^{*}}$ and Toomas TAMMARU ${ }^{1,3}$ \\ 'Institute of Zoology and Hydrobiology, Vanemuise 46, Tartu University, 51014 Tartu, Estonia; \\ ${ }^{2}$ Section of Ecology, Department of Biology, University of Turku, FIN-20014 Turku, Finland; \\ ${ }^{3}$ Institute of Zoology and Botany, Riia 181, 51014 Tartu, Estonia
}

Key words. Body size, parasitism risk, parasitoids, phenology, preference-performance linkage, life-history, Epirrita autumnata, Geometridae.

\begin{abstract}
The effect of larval body size of Epirrita autumnata (Lepidoptera, Geometridae) on the risk of parasitism was studied in a field experiment. The experiment involved three pairwise exposures of different larval instars to parasitoids. Three hymenopteran species were responsible for most of the parasitism. Parasitism risk was found to be host-instar independent. This result was consistent across parasitoid species and experiments. The results suggest that host use by larval parasitoids cannot constrain selection for larger body size in E. autumnata. However, high mortality due to parasitism may select for a short developmental period (the slowgrowth/high-mortality hypothesis), and smaller body sizes as a by-product. A strong selective effect of parasitism on the timing of larval development in E. autumnata is also unlikely. The larger was the host, the larger was the adult size of the parasitoid and the shorter its development time (for one species). We suggest that the lack of a preference-performance linkage in the system studied may be related to the time stress associated with the short phenological window of host vulnerability.
\end{abstract}

\section{INTRODUCTION}

In insects, fecundity is often strongly correlated with the body size of the female (Honěk, 1993). Such a correlation implies a persistent selection for large adult size. We are thus justified in asking what selective forces balance this obvious fecundity advantage, and prevent a continuous evolutionary increase in insect body size. The answer is intuitively related to elevated mortality risks, but it is not necessarily a trivial one (Leimar, 1996; Tammaru, 1998). In particular, for Epirrita autumnata (Borkhausen) (Lepidoptera: Geometridae), an optimality analysis (Tammaru, 1998) showed that realistic values of constant, body-size independent larval mortality rates and seasonal changes in host plant quality are insufficient to explain why these insects do not grow larger by prolonging their larval growth. However, if large larvae are more likely to be killed, the resulting positively body-size dependent mortality might be the ecological factor capable of balancing the fecundity advantage of large body size.

Parasitoids are often one of the main causes of mortality in herbivorous insects, and affect various ecological traits of their hosts. The traits affected include food plant preference (Ohsaki \& Sato, 1990, 1994; Björkman et al., 1997), and timing of life-history switches (McGregor, 1996). Numerous laboratory experiments, and some field studies have shown that parasitism risk may depend on host body size, and the dependence being often mediated via behavioural responses of the parasitoids (e.g. van
Alphen \& Drijver, 1982; Nealis, 1990; Sait et al., 1997). Either small or large hosts may experience a higher risk of parasitism in different host-parasitoid systems; adaptive explanations for these patterns are largely based on differences in parasitoid life-histories, especially koinobiosis and idiobiosis (Harvey, 1996, Harvey et al., 2000; Strand, 2000). Host-size dependent parasitism is usually discussed from a parasitoid's perspective, while the importance of this phenomenon in shaping the life-history of the host has received markedly less attention (see, however, Solbreck et al., 1989; Teder et al., 1999).

To assess the role of parasitism as a selective agent acting on host body size, we conducted field experiments and recorded the incidence of parasitism of different sized larvae of $E$. autumnata. We asked if the risk of sizedependent parasitism could balance the high fecundity advantage of large female size (Tammaru et al., 1996). In addition, the design of the experiments enabled us to assess whether parasitism affected the phenology of the herbivore. Finally, we briefly discuss whether parasitoids benefit from size-selective use of the host in the system studied, and propose an explanation for the observed patterns of size selectivity.

\section{MATERIAL AND METHODS}

\section{Study species}

Epirrita autumnata, the autumnal moth, is a medium-sized holarctic lepidopteran known for its tendency to achieve outbreak levels of abundance in northern and mountainous Fennoscandia (Tenow, 1972; Haukioja et al., 1988; Ruohomäki et

\footnotetext{
* Corresponding author. Institute of Zoology and Botany, Riia 181, 51014 Tartu, Estonia; e-mail: tiit@zbi.ee
} 
al., 2000). The populations are stable elsewhere. The species has a univoltine life cycle. The eggs overwinter and hatch in spring. The solitary, cryptic larvae feed on deciduous trees and shrubs E. autumnata is a typical flush-feeder (=spring feeder): its larval performance is critically dependent on the phenological stage of the foliage (Ayres \& MacLean, 1987; Kaitaniemi et al., 1998; Kause et al., 1999). Larval development lasts for about one month and consists invariably of 5 larval instars (Tammaru, 1998). A 5th instar larva may reach $\approx 40 \mathrm{~mm}$ in length and 150 $\mathrm{mg}$ in weight, the size gain per instar being roughly two-fold for length, and four-fold for weight. They develop relatively synchronously, but larvae of two or three different instars may still occur at the same time. Pupation occurs in the ground in early June, and the adults emerge in early autumn.

Larvae of E. autumnata are attacked by several hymenopteran parasitoids (Ruohomäki, 1994; Kaitaniemi \& Ruohomäki, 1999; Teder et al., 2000). The most common encountered in the present study were the three solitary koinobiont species: Protapanteles immunis (Haliday) and Cotesia jucunda (Marsh.) (both Braconidae), and an unidentified species of Campoletis (Ichneumonidae). The two former species (2.5-3.5 $\mathrm{mm}$ in length) are bivoltine generalists parasitising various geometrids (Tobias, 1986). Their development from oviposition to pupation (i.e. emergence from host larvae) takes about 3 weeks. The body length of the Campoletis sp. is $6-8 \mathrm{~mm}$, and irrespective of the host instar parasitised, it always emerges from the prepupa of its host.

\section{Study areas and sites}

The two-year (1998-1999) experimental field study was carried out in two forested areas outside the range where outbreaks of $E$. autumnata occur: 1) about $20-30 \mathrm{~km}$ northeast of the town of Turku $\left(60^{\circ} 15^{\prime} \mathrm{N}, 22^{\circ} 25^{\prime} \mathrm{E}\right)$, southwestern Finland (1998), and 2) near the town of Tartu $\left(58^{\circ} 22^{\prime} \mathrm{N} ; 26^{\circ} 45^{\prime} \mathrm{E}\right)$, southeastern Estonia (1999). The experiments were conducted at a total of twelve sites, four sites in 1998 (within an area $\approx 10 \mathrm{~km}^{2}$ ) and eight in 1999 (within an area of $\approx 2 \mathrm{~km}^{2}$ ). Most of the study sites were mixed coniferous forests, dominated by Pinus sylvestris L. or Picea abies (L.) Karsten with birches (Betula pubescens (Ehrhart) and also B. pendula (Roth) in some sites) growing in the understory.

\section{Experiment design}

To determine if parasitoids preferably attack certain larval instars of $E$. autumnata, three separate host choice experiments were conducted. At each of the 12 study sites, 16-20 birches (mostly B. pubescens, occasionally $B$. pendula), $1-1.8 \mathrm{~m}$ in height, separated by distances of 5 to $10 \mathrm{~m}$, were chosen Laboratory-reared larvae of two different instars were released onto the experimental trees. Three combinations of instars were used; larvae moulting either into the 1) second and third instars (conducted at four sites in 1998), 2) second and fourth instars (four sites in 1999), or 3) third and fourth instars (four sites in 1999). The numbers of larvae of each instar released were equal on each tree (e.g. 5 second and 5 third instar larvae). The total number of larvae used in the three experiments was 1452 . In each experiment, two densities were created, with ten $(5+5)$ and four larvae $(2+2)$ on $40 \%$ and $60 \%$ of the trees, respectively. These host densities correspond to those during minor and moderate outbreaks of E. autumnata, and greatly exceeded the natural background densities in the study area. Using two different densities was motivated by the original idea, which was to study the effects of host density, as an additional factor, on size-selectivity in host use. However, a subsequent data analysis showed that larval density did not affect the patterns of parasit- ism. For the sake of clarity of presentation, we do not incorporate this factor in the further analyses.

Larvae were exposed to parasitoids for a period corresponding to the duration of about one instar (7-8 days). The experiments were performed at the time when laboratory-reared larvae were approximately of the same age as those in the field. After the exposure period, the released larvae were collected and reared in the laboratory until they pupated or a parasitoid emerged. For the parasitoids the dates of emergence and the length of hind tibia, as measure of body size, were recorded. Parasitoid size was used to assess the profitability of different host instars for the parasitoids.

\section{Data analysis}

To determine if risk of parasitism differed for different larval instars, the data were analysed using generalised linear models (SAS PROC GENMOD, SAS Institute Inc., 1995). Parasitism status of a host (parasitised/unparasitised) was treated as the binary dependent variable, instar (second and third; second and fourth; third and fourth instars in the respective analyses) and study site as the categorical independent variables. Binomial distribution was assumed and logit was used as the link function. In additional analyses, parasitism caused by the most common species of parasitoids was considered separately. Finally, an analogous analysis of the total parasitism was performed with the data from the three experiments combined. Larval instar was then coded on the relative binary scale (younger instar/older instar) in each particular experiment, irrespective of the instars involved.

Larvae that were not recovered from the field ( $44 \%$ of the larvae, pooled over study sites and experiments) and those that died in the laboratory before pupation or emergence of a parasitoid (about $10 \%$ of the larvae) were not included in the statistical analyses. To analyse the effect of host instar on adult body size of parasitoids, a two-way analysis of variance was applied, with parasitoid sex as an additional factor. Student t-test was applied to test the effect of host instar on parasitoid development time.

\section{RESULTS}

\section{Distribution of parasitism among larval instars}

Parasitism rate was highly variable between study sites, varying from a few to about 75 percent. Species composition of the parasitoids was also very differ (Table 1). Parasitism risk was host-instar independent when parasitoids were given a choice between second and third instar larvae (Table 1a, 2a). Consistently, the levels of parasitism by each of the two dominant parasitoids ( $C$. jucunda and $P$. immunis) did not differ between instars $\left(D F=1, \chi^{2}=0.03, p=0.87\right.$, and $D F=1, \chi^{2}=1.96$, $p=0.16$, respectively). Other parasitoids were present in numbers too low for a meaningful analysis.

The most numerous parasitoid in the Estonian experiments, Campoletis sp., showed no preference for a particular host instar, neither when second and fourth instars, nor when third and fourth instars were simultaneously exposed $\left(D F=1, \chi^{2}=0.16, p=0.69\right.$, and $D F=1$, $\chi^{2}=1.27, p=0.26$, respectively). Other parasitoids were too scarce to analyse separately. The levels of total parasitism did not differ significantly between instars in the experiment in which second and fourth instars were exposed to parasitoids (Table 1b, 2b). However, there was a slightly lower level of total parasitism of fourth 
TABle 1. Percentage parasitism of two simultaneously exposed larval instars of $E$. autumnata. Sample sizes refer to the numbers of larvae recovered (by instar) and used in the analyses.

\begin{tabular}{|c|c|c|c|c|c|c|c|c|}
\hline $\begin{array}{l}\text { Site } \\
\text { (sample size) }\end{array}$ & $\begin{array}{l}\text { Percent } \\
\text { by } C a\end{array}$ & $\begin{array}{l}\text { rasitism } \\
\text { tis sp. }\end{array}$ & $\begin{array}{r}\text { Percenta } \\
P\end{array}$ & $\begin{array}{l}\text { itism by } \\
\text { is }\end{array}$ & Percent & $\begin{array}{l}\text { itism by } \\
a\end{array}$ & Total pe & e para- \\
\hline a) $2 \mathrm{nd}$ and $3 \mathrm{rd}$ & ars (Finla & & & & & & & \\
\hline & 2nd & $3 \mathrm{rd}$ & 2nd & $3 \mathrm{rd}$ & 2nd & $3 r d$ & 2nd & $3 r d$ \\
\hline $1(41 / 41)$ & - & - & 2.4 & 2.4 & - & - & 2.4 & 2.4 \\
\hline $2(34 / 48)$ & - & - & 17.6 & 8.3 & - & - & 17.6 & 8.3 \\
\hline $3(36 / 39)$ & - & - & - & - & 38.9 & 43.6 & 38.9 & 43.6 \\
\hline $4(44 / 49)$ & - & - & 2.3 & 0 & 2.3 & 0 & 4.5 & 0 \\
\hline b) $2 \mathrm{nd}$ and 4 th & ars (Estol & & & & & & & \\
\hline & $2 \mathrm{nd}$ & 4th & 2nd & 4th & 2nd & 4th & 2nd & 4th \\
\hline $5(12 / 26)$ & - & - & 8.3 & 0 & 8.3 & 3.8 & 16.7 & 3.8 \\
\hline $6(9 / 27)$ & 22.2 & 18.5 & 11.1 & 0 & 11.1 & 0 & 44.4 & 18.5 \\
\hline $7(8 / 14)$ & 12.5 & 50 & - & - & 12.5 & 0 & 25 & 50 \\
\hline $8(8 / 28)$ & 75 & 60.7 & - & - & 12.5 & 3.6 & 87.5 & 64.3 \\
\hline c) $3 \mathrm{rd}$ and 4 th & rs (Eston & & & & & & & \\
\hline & $3 \mathrm{rd}$ & 4th & $3 \mathrm{rd}$ & 4 th & $3 \mathrm{rd}$ & 4th & $3 \mathrm{rd}$ & 4th \\
\hline $9(39 / 43)$ & 2.6 & 4.7 & - & - & 2.6 & 0 & 7.7 & 4.7 \\
\hline $10(37 / 41)$ & 18.9 & 12.2 & - & - & - & - & 24.3 & 12.2 \\
\hline $11(23 / 34)$ & 47.8 & 29.4 & - & - & 8.7 & 2.9 & 60.9 & 35.3 \\
\hline $12(14 / 30)$ & 35.7 & 36.7 & - & - & - & - & 57.1 & 40 \\
\hline
\end{tabular}

instar larvae when they were exposed with third instar larvae (Table 1c, 2c). This difference was due to parasitoids other than Campoletis sp. (a few C. jucunda among these).

Consistently, an analysis of the data pooled over the experiments did not support the notion that the larger larvae are more likely to be parasitised, rather the reverse. The corresponding tendency, however only approached statistical significance (Table 2d). Calculated for the entire data set, $23.6 \%$ of the younger vs $20.0 \%$ of the older larvae were parasitised $(\mathrm{N}=725)$. The $95 \%$ confidence limits of the ratio of these values (lower 0.89 , upper 1.56, SAS PROC FREQ CLI option) gives a simple but illustrative power estimate of this analysis.

\section{Effect of host instar on parasitoid development}

Body size of the offspring of Campoletis sp. significantly increased with host instar (two-way ANOVA with parasitoid sex as an additional factor: $F_{2,62}=8.20, p<$ 0.001 ; all three pairwise contrasts between instars were significant; sites pooled). The average lengths of the hind tibia of parasitoids from second, third and fourth instars were $1.87,1.94$ and $1.98 \mathrm{~mm}$, respectively. Similarly, body size of $C$. jucunda significantly increased with host instar (one-way ANOVA: $F_{I, 16}=7.10, p=0.02$; females only, only one male emerged). The average lengths of the hind tibia of C. jucunda that developed in the hosts' second and third instars were $0.99 \mathrm{~mm}$ and $1.02 \mathrm{~mm}$, respectively. The number of $C$. jucunda emerging from fourth instar hosts was too low for analysis. Most individuals of $P$. immunis, the third most common parasitoid, failed to emerge from their cocoons. The effect of host instar on their body size could thus not be estimated.
Host instar strongly affected developmental period in Campoletis sp. but not in C. jucunda or P. immunis. In Campoletis, exact timing of parasitoid emergence could not be recorded due to the below-ground pupation of the host. However, irrespective of the host instar parasitised, parasitoid larvae invariably emerged from host prepupae. This allows us to conclude that parasitising a younger instar larva would add an extra week to the parasitoid's development time. In contrast, there was no effect of host instar on the parasitoid's development time in the remaining two species (C. jucunda: $t=0.44, D F=29$, $p=0.67 ;$. immunis: $t=0.09, D F=11, p=0.93$ ).

\section{DISCUSSION}

There was no evidence of a positively size-dependent parasitism risk in E. autumnata. The only experiment where a significant difference in parasitism rates was detected, suggested the opposite: the smaller larvae suffered more parasitism (Table 1, 2c). A combined analysis of the effects of host size on the incidence of parasitism also indicated a greater risk for the smaller larvae rather than vice versa (Table $2 \mathrm{~d}$ ). Risk of larval parasitism is thus not likely to balance the strong fecundity advantage (Tammaru et al., 1996) of large size in females of $E$. autumnata.

However, even if mortality due to larval parasitism cannot alone provide a sufficient adaptationist explanation for body size in $E$. autumnata, parasitoids may still be a factor determining the cost of large adult size. According to the slow-growth/high-mortality hypothesis, longer developmental periods often imply higher vulnerability to predation and/or parasitism (Loader \& Damman, 1991; Häggström \& Larsson, 1995; Benrey \& 
TABLE 2. Results of analyses of the effect of host instar (relative size in d) - see text) on the incidence of total parasitism.

\begin{tabular}{lccc}
\hline Source & $D F$ & $\chi^{2}$ & $p$ \\
\hline a) 2nd and 3rd instars & & & \\
$\quad$ Site & 3 & 62.96 & $<0.001$ \\
$\quad$ Instar & 1 & 0.54 & 0.46 \\
b) 2nd and 4th instars & & & \\
$\quad$ Site & 3 & 36.38 & $<0.001$ \\
$\quad$ Instar & 1 & 1.99 & 0.16 \\
c) 3rd and 4th instars & & & \\
$\quad$ Site & 3 & 46.62 & $<0.001$ \\
Instar & 1 & 6.77 & 0.009 \\
d) All experiments combined & & & \\
$\quad$ Experiment & 2 & 30.13 & $<0.001$ \\
$\quad$ Size & 1 & 3.55 & 0.06 \\
\hline
\end{tabular}

Denno, 1997). In terms of daily survival, the larval stage is definitely the most vulnerable one in the life cycle of $E$. autumnata (Tanhuanpää et al., 1999, 2001). Mortality of larvae attributable to parasitoids may reach levels (Ruohomäki, 1994; Teder et al., 2000, and this study) that exceed mortalities in other stages of the life cycle combined. This should favour short developmental periods.

In contrast to parasitism, large larvae may be at a greater risk of bird predation than small. In particular, Tanhuanpää et al. (2001) showed that mortality due to bird predation was considerably higher during late instars than early instars. However, the design of these experiments does not allow the separation of the effects of time and size: larger larvae occurred later in the season when, e.g., the foraging activity of birds could have been higher. The effect of other principal predators, ants and spiders, was shown to be spatially restricted and presumably of less importance.

The present study also suggests that parasitism creates no significant selective pressure on the phenology of the larval stage in E. autumnata. In particular, our experiments may be alternatively interpreted as exposing larvae of different ages. In this context the results suggest that neither the larvae that are ahead nor behind the average in development suffer from increased levels of parasitism. These results complement those of Kaitaniemi and Ruohomäki (1999) who showed that the flight period of most E. autumnata parasitoids exceeds the larval period of the host: larvae reared outside the normal time schedule did not escape parasitism. Combined with the results of the present study, this observation allows us to exclude parasitism as an important selective force acting on the timing of larval development in E. autumnata. The need to synchronise larval development with suitable host plant phenology is apparently a much stronger determinant of the optimal hatching date of the larvae (Ayres \& MacLean, 1987; Kaitaniemi et al., 1998).

Parasitoids appeared to benefit from developing in late instars of $E$. autumnata: body size of adult parasitoids was positively correlated with host size. Additionally, Campoletis $\mathrm{sp}$. showed considerable host-instar dependent variation in development time. Both these variables have important fitness consequences: body size is frequently a good indicator of fecundity (Harvey et al., 1994; Sequeira \& Mackauer, 1994; Ellers et al., 1998), while a short development time may imply reduced risk of mortality during preimaginal stages (Price, 1972; Slansky, 1986; Godfray, 1994). The latter is apparently true for $E$. autumnata parasitoids as well: high predation rates of moths during the larval stage (Tanhuanpää et al., 2001) imply a high mortality risk for juvenile parasitoids. However, different profitabilities of parasitising differently-aged larvae did not lead to a preferenceperformance linkage, a phenomenon demonstrated in numerous laboratory studies on insect parasitoids (e.g. van Alphen \& Drijver, 1982; Liu et al., 1984, Liu, 1985; Hopper, 1986).

Parasitoids may use suboptimally sized hosts for a variety of reasons, e.g. because of their size-dependent apparency (van Alphen \& Drijver, 1982) or behavioural defence (van Alphen \& Drijver, 1982; Brodeur et al., 1996; Harvey, 1996; Chau \& Mackauer, 2000), or agedependent survival in hosts (especially koinobiont parasitoids: Driessen et al., 1991; Sequeira \& Mackauer, 1994; Brodeur \& Vet, 1995). Although this study did not address the question of the causes of the non-selective host use, we would like to highlight a potential explanation specific to the system studied. In particular, the larvae of flush feeders like E. autumnata pass quickly and synchronously through the larval stage. The parasitoids of these moths are thus likely to be time-rather than egglimited and the resulting time-stress should favour lower selectivity (cf. Jaenike, 1990; Mayhew, 1997, for examples with herbivorous insects). Moreover, in E. autumnata, high levels of larval parasitism (Teder et al., 2000, and this study) suggest strong intra- and interspecific exploitative competition among parasitoids that further contributes to the ephemeral character of the resource for parasitoids. This, in turn, should select for high oviposition rates, and reduced selectivity as a correlated response.

ACKNOWLEDGEMENTS. We thank Grant Gentry, Jeffrey A. Harvey, Antti Kause and an anonymous referee for their helpful comments, and Tommi Andersson, Rein Karulaas, Pille Kõiv, Kai Ruohomäki, Siiri-Lii Sandre and Miia Tanhuanpää for field assistance. The study was partly supported by the Estonian Science Foundation (grant no. 4076) and the Kone Foundation.

\section{REFERENCES}

Alphen van J.J.M. \& DriJver R.A.B. 1982: Host selection by Asobara tabida Nees (Braconidae; Alysiinae) a larval parasitoid of fruit inhabiting Drosophila species. I. Host stage selection with Drosophila melanogaster as host species. Neth. J. Zool. 32: 215-231.

AYres M.P. \& MACLEAN S.F.Jr. 1987: Development of birch leaves and the growth energetics of Epirrita autumnata (Geometridae). Ecology 68: 558-568.

BenRey B. \& Denno R.F. 1997: The slow-growth-high-mortality hypothesis: a test using the cabbage butterfly. Ecology $\mathbf{7 8}$ : 987-999. 
BjörkMan C., LaRsson S. \& Bommarco R. 1997: Oviposition preferences in pine sawflies: a trade-off between larval growth and defence against natural enemies. Oikos 79: 45-52.

Brodeur J., Geervliet J.B.F. \& Vet L.E.M. 1996: The role of host species, age and defensive behaviour on ovipositional decisions in a solitary specialist and gregarious generalist parasitoid (Cotesia species). Entomol. Exp. Appl. 81: 125-132.

BRODEUR J. \& VET L.E.M. 1995: Relationships between parasitoid host range and host defence: a comparative study of egg encapsulation in two related parasitoid species. Physiol. Entomol. 20: 7-12.

Chau A. \& Mackauer M. 2000: Host-instar selection in the aphid parasitoid Monoctonus paulensis (Hymenoptera: Braconidae, Aphidiinae): a preference for small pea aphids. Eur. J. Entomol. 97: 347-353.

Ellers J., van Alphen J.J.M. \& SeVenster J.G.A. 1998: A field study of size-fitness relationships in the parasitoid Asobara tabida. J. Anim. Ecol. 67: 318-324.

Driessen G., Hemerik L. \& Boonstra B. 1991: Host selection behaviour of the parasitoid Leptopilina clavipes, in relation to survival in hosts. Neth. J. Zool. 41: 99-111.

Godfray H.C.J. 1994: Parasitoids: Behavioral and Evolutionary Ecology. Princeton University Press, Princeton, New Jersey, $473 \mathrm{pp}$

HäGgSTRÖM H. \& LARSSON S. 1995: Slow larval growth on a suboptimal willow results in high predation mortality in the leaf beetle Galerucella lineola. Oecologia 104: 308-315.

HaRveY J.A. 1996: Venturia canescens parasitizing Galleria mellonella and Anagasta kuehniella: is the parasitoid a conformer or regulator? J. Insect Physiol. 42: 1017-1025.

Harvey J.A., Harvey I.F. \& Thompson D.J. 1994. Flexible larval growth allows use of a range of host sizes by a parasitoid wasp. Ecology 75 : 1420-1428.

HaRvey J.A., Kadash K. \& Strand M.R. 2000: Differences in larval feeding behavior correlate with altered developmental strategies in two parasitic wasps: implications for the size- fitness hypothesis. Oikos 88: 621-629.

Haukioja E., Neuvonen S., Hanhimäki S. \& Niemelä P. 1988 The autumnal moth in Fennoscandia. In Berryman A. (ed.): Dynamics of Forest Insect Populations: Patterns, Causes, Implications. Plenum Press, New York, pp. 163-178.

HONĚK A. 1993: Intraspecific variation in body size and fecundity in insects: a general relationship. Oikos 66: 483-492.

HoPPER K. 1986: Preference, acceptance, and fitness components of Microplitis croceipes (Hymenoptera: Braconidae) attacking various instars of Heliothis virescens (Lepidoptera: Noctuidae). Environ. Entomol. 15: 274-280.

JAENIKE J. 1990: Host specialization in phytophagous insects. Annu. Rev. Ecol. Syst. 21: 243-273.

Kaitaniemi P., Ruohomäki K., Ossipov V., Haukioja E. \& PiHLAJA K. 1998: Delayed induced changes in the biochemical composition of host plant leaves during an insect outbreak. Oecologia 116: 182-190.

Kaitaniemi P. \& Ruohomäki K. 1999: Effects of autumn temperature and oviposition date on timing of larval development and risk of parasitism in a spring folivore. Oikos 84: 435-442.

Kause A., Saloniemi I., Haurrioja E. \& Hanhimäki S. 1999: How to become large quickly: quantitative genetics of growth and foraging in a flush feeding lepidopteran larva. J. Evol. Biol. 12: 471-482.

LeIMAR O. 1996: Life history plasticity: influence of photoperiod on growth and development in the common blue butterfly. Oikos 76: $228-243$.
Liu Shu-sheng 1985: Development, adult size and fecundity of Aphidius sonchi reared in two instars of its aphid host, Hyperomyzus lactucae. Entomol. Exp. Appl. 37: 41-48.

Luu Shu-sheng, Morton R. \& Hughes R.D. 1984: Oviposition preferences of a hymenopterous parasite for certain instars of its aphid host. Entomol. Exp. Appl. 35: 217-220.

LOADER C. \& Damman H. 1991: Nitrogen content of food plants and vulnerability of Pieris rapae to natural enemies. Ecology 72: $1586-1590$.

MAYHEW P.J. 1997: Adaptive patterns of host plant selection by phytophagous insects. Oikos 79: 417-428.

MCGREGOR R. 1996: Phenotypic selection by parasitoids on the timing of life history in a leaf-mining moth. Evolution 50: $1579-1584$.

NeAlis V.G. 1990: Factors affecting the rate of attack by Cotesia rubecula (Hymenoptera: Braconidae). Ecol. Entomol. 15: $163-168$.

Ohsaki N. \& Sato Y. 1990: Avoidance mechanisms of three Pieris butterfly species against the parasitoid wasp Apanteles glomeratus. Ecol. Entomol. 15: 169-176.

Ohsaki N. \& Sato Y. 1994: Food plant choice of Pieris butterflies as a trade-off between parasitoid avoidance and quality of plants. Ecology 75: 59-68.

Price P.W. 1972: Parasitoids utilizing the same host: adaptive nature of differences in size and form. Ecology 53: 190-195.

RUOHOMÄKI K. 1994: Larval parasitism in outbreaking and nonoutbreaking populations of Epirrita autumnata (Lepidoptera, Geometridae). Entomol. Fennica 5: 27-34.

Ruohomäki K., Tanhuanpä̈ M., Ayres M., Kaitaniemi P., TamMARU T. \& Haukioja E. 2000: Causes of cyclicity of Epirrita autumnata (Lepidoptera, Geometridae) - grandiose theory and tedious practice. Popul. Ecol. 42: 211-223.

Sait S.M., Begon M., Thompson D.J., Harvey J.A. \& Hails R.S. 1997: Factors affecting host selection in an insect hostparasitoid interaction. Ecol. Entomol. 22: 225-230.

SAS Institute Inc. 1995: SAS/STAT Users Guide. Version 6.10. SAS Institute Inc., Cary, North Carolina.

Sequerra R. \& Mackauer M. 1994: Variation in selected lifehistory parameters of the parasitoid wasp, Aphidius ervi: influence of host developmental stage. Entomol. Exp. Appl. 71: 15-22.

SLANSKY F. Jr 1986: Nutritional ecology of endoparasitic insects and their hosts: an overview. J. Insect Physiol. 32: 255-261.

Solbreck C., Olsson R., Anderson D.B. \& Förare J. 1989: Size, life history and responses to food shortage in two geographical strains of a seed bug Lygaeus equestris. Oikos 55: 387-396.

Strand M.R. 2000: Developmental traits and life-history evolution in parasitoids. In Hochberg M.E. \& Ives A.R. (eds): Parasitoid Population Biology. Princeton University Press, Princeton, pp. 139-162.

TAMmaru T. 1998: Determination of adult size in a folivorous moth: constraints at instar level? Ecol. Entomol. 23: 80-89.

TAmmaru T., Kaitaniemi P. \& RưhOMäkI K. 1996: Realized fecundity in Epirrita autumnata (Lepidoptera: Geometridae): relation to body size and consequences to population dynamics. Oikos 77: 407-416.

Tanhuanpää M., RuohomäKi K., Kaitaniemi P. \& Kiemola T. 1999: Different impact of pupal predation on populations of Epirrita autumnata (Lepidoptera; Geometridae) within and outside the outbreak range. J. Anim. Ecol. 68: 562-570.

TanhuanpäÄ M., RuohomäKi K. \& UUsipaikka E. 2001: High larval predation rate in non-outbreaking populations of a geometrid moth. Ecology 82: 281-289. 
Teder T., Tammaru T. \& Pedmanson R. 1999: Patterns of host use in solitary parasitoids (Hymenoptera, Ichneumonidae) field evidence from a homogenous habitat. Ecography 22: $79-86$.

Teder T., Tanhưanpää M., Rưohomäki K., Kaitaniemi P. \& Henriksson J. 2000: Temporal and spatial variation of larval parasitism in non-outbreaking populations of a folivorous moth. Oecologia 123: 516-524.
TENow O. 1972: The Outbreaks of Oporinia Autumnata Bkh. and Operophthera spp. (Lep., Geometridae) in the Scandinavian Mountain Chain and Northern Finland 1862-1968. Ph.D. Thesis, University of Uppsala, Uppsala, $107 \mathrm{pp}$.

ToBIas V.I. 1986: Subfamily Microgasterinae. In Tobias V.I. (ed.): Key to the Insects of the European Part of the USSR, Volume 3 (part 4). Nauka, Leningrad, pp. 344-459. (In Russian).

Received November 16,2000; revised May 18, 2001; accepted June 21, 2001 